\title{
PARADIGMAS E PERSPECTIVAS DA INTERVENÇÃO JUDICIAL EM POLÍTICAS PÚBLICAS
}

\section{PARADIGMS AND PERSPECTIVES OF JUDICIAL REVIEW OF PUBLIC POLICIES}

\section{Emilie Kalyne Munhoz Paulo Henrique Veloso da Conceição*}

SUMÁRIO: Introdução. 1 Do Estado Liberal ao Estado Democrático de Direito. 2 Direitos Fundamentais: posição e significado na Constituição de um Estado Democrático de Direito. 3 Os Direitos Sociais à luz da Constituição de 1988: o problema da eficácia e aplicabilidade. 4 As políticas públicas como instrumento de concretização dos direitos sociais e o controle judicial de políticas públicas. 5 Limites à intervenção judicial em políticas públicas. 5.1 A separação de poderes e a democracia. 5.2 A garantia do mínimo existencial. 5.3 A reserva do possível. 6 A crítica operacional ao controle judicial de políticas públicas. 7 Judicialização de políticas públicas: necessidade de um novo procedimento?. Conclusão. Bibliografia.

RESUMO: O presente artigo pretende analisar a efetivação dos direitos fundamentais através do controle judicial de políticas públicas. Para tanto, traça em linhas gerais a evolução do Estado Liberal ao Estado Democrático de Direito, que permitiu que os direitos fundamentais ganhassem maior relevância jurídica, política e socioeconômica. É neste contexto que o Judiciário, ao controlar as políticas públicas, se torna verdadeiro prestador de serviços aos jurisdicionados e concretizador dos direitos fundamentais a nível transindividual. Entretanto, tal controle é sujeito a determinados limites traçados pela doutrina e jurisprudência: a separação de poderes; a "reserva do possível" e a "garantia do mínimo existencial". É pela extrema complexidade envolvendo estas demandas que hoje debate-se a necessidade de um procedimento especial para o controle judicial de políticas públicas.

Palavras-chave: direitos fundamentais. direitos sociais. controle judicial de políticas públicas. políticas públicas.

ABSTRACT: This article has the intention to discuss the promotion of fundamental rights trough judicial review of public policies. First it addresses the transition of Liberal State to a Democratic Constitutional State to point out the importance and

\footnotetext{
Advogada. Possui graduação em direito pela Universidade Estadual Paulista. Pós graduanda em Direito Civil Constitucional pela Universidade do Estado do Rio de Janeiro. Mestranda em Direito e Políticas Públicas pela Universidade Federal do Estado do Rio de Janeiro.

Advogado. Graduado em Direito pela UNESP - Universidade Estadual Paulista “Júlio de Mesquita Filho". Mestrando em Direito Processual pela UERJ - Universidade do Estado do Rio de Janeiro.
} 
relevance of fundamental rights and how this new reality has influences in the behavior of public authorities. These changes increased the claims about the violation of fundamental that is represented by the inexistence or inefficiency of public policies. In this context the Judiciary had - and still have - to review their role and function in a society that is much in need of social and economic development. That is one of the reasons that today has been discussed the need of a special procedure to solve these difficult demands.

Key-words: fundamental rights. social rights. judicial review. public policies.

\section{INTRODUÇÃO}

Os efeitos oriundos do Estado liberal - individualismo, abstencionismo estatal - provocaram imensas injustiças sociais, o que desencadeou um novo modelo estatal: o Estado Social de Direito. Não obstante este modelo preconizasse a amortização das lutas de classe e a tão almejada justiça social, através da redução das desigualdades materiais, não logrou êxito. Foi então que surgiu o modelo institucional do Estado Democrático de Direito, que incorporou em sua essência a árdua tarefa de transformação do status quo.

A Constituição da República de 1988, em seu art. $1^{\circ}$, adotou expressamente este último modelo institucional. Sob esta nova concepção de constitucionalismo, os direitos fundamentais se elevam ao patamar de verdadeiros garantidores da justiça social e tornam-se prérequisitos para a promoção da liberdade e da dignidade da pessoa humana, genuínos pilares da evolução humana e social.

O princípio constitucional da eficácia plena e da aplicabilidade imediata dos direitos fundamentais (art. $5^{\circ}, \S 1^{\circ}, C F$ ) é a representação desta força constitucional. Trata-se de uma limitação da liberdade de agir, que é imposta a todos os destinatários das normas constitucionais sejam de caráter público ou privado -, os quais se encontram subordinados à própria natureza dos direitos fundamentais.

Assim, os direitos fundamentais tornam-se, após a consolidação do Estado Democrático de Direito, verdadeiros instrumentos de legitimação do poder estatal, com a característica de vincular os atos praticados pelos representantes dos poderes Executivo, Legislativo e Judiciário aos exatos limites delineados na Carta Política de 1988. Tais direitos não só determinam a observância dos seus limites constitucionais, como também impõem ao poder estatal o empenho de esforços para a concretização e efetivação destes direitos. 
Com a transição do Estado Liberal para o Estado Democrático de Direito, o Poder Judiciário ganhou um novo perfil. Passou, a partir de então, a ser não mais mero aplicador da lei, mas uma vertente do poder estatal com atuação direta na sociedade, incumbido da missão constitucional atribuída pelo art. $3^{\circ}$, da Constituição Federal de 1988: construir uma sociedade livre, justa e solidária; garantir o desenvolvimento nacional; erradicar a pobreza e a marginalização e reduzir as igualdades sociais e regionais; e promover o bem de todos.

É neste contexto que se proliferam, no Judiciário, demandas buscando a efetivação de direitos fundamentais por intermédio das políticas públicas, seja exigindo ao Poder Público a implementação de uma política inexistente, seja questionando a efetividade da política pública adotada pelo agente público, seja determinando ao Legislativo a sua inclusão no orçamento seguinte.

As políticas públicas, antes sujeitas apenas à discricionariedade do Poder Público, passaram a ter seu mérito enfrentado pelo Poder Judiciário, que, na condição de guardião máximo da Constituição, não deve medir esforços para garantir a concretização e efetivação dos direitos fundamentais (art. $5^{\circ}, \S 1^{\circ}$, da $\mathrm{CF}$ ).

Diante destas demandas, o Poder Judiciário encontrou obstáculos, muitas vezes, intransponíveis, pois os verdadeiros responsáveis pela definição e implementação de políticas públicas seriam, respectivamente, os poderes Executivo e Legislativo.

Uma intervenção sem limites do Judiciário em matéria de políticas públicas poderia transgredir a cláusula pétrea da tripartição de poderes, bem como o princípio da democracia, desestabilizando irreversivelmente o orçamento público ou até mesmo intervindo imotivadamente na discricionariedade administrativa.

Daí a necessidade do estabelecimento de limites à atuação judiciária, traçados pela doutrina e jurisprudência, como a chamada "reserva do possível", a garantia do "mínimo existencial" e o princípio da razoabilidade, limites estes que possuem o escopo de garantir a legitimidade à intervenção judicial em políticas públicas.

Por todos os obstáculos enfrentados pelo Poder Judiciário nesta trajetória, bem como pela proliferação do fenômeno da judicialização das políticas públicas, é que hoje se faz imprescindível o estudo aprofundado destas transformações sócio-jurídicas. 


\section{DO ESTADO LIBERAL AO ESTADO DEMOCRÁTICO DE DIREITO $^{1}$}

A organização política e econômica de um Estado possui influência direta na proteção e garantia dos direitos fundamentais. Com efeito, um Estado pode possuir, ao longo de seu desenvolvimento, traços mais característicos do modelo liberal, ou, ao contrário, pode prezar por intervenções típicas do Estado Social ou do modelo Democrático de Direito. Apesar da possível coexistência simultânea destes modelos em um mesmo Estado, houve, ao decorrer da história, a predominância de determinados modelos. É o que se passa a analisar a seguir.

É no período de transição formal do Estado Liberal para o Estado Democrático de Direito, principalmente após o período das duas grandes guerras, que as lutas sociopolíticas pela efetivação dos direitos humanos ganham rigidez, notoriedade e alcance internacional.

O Estado Liberal, ou Estado de legalidade, assim entendido como verdadeiro guardião das liberdades individuais, alcançou sua consolidação histórica a partir da Revolução Francesa, ocasião em que a burguesia formulou os princípios jusfilosóficos de sua insatisfação social, com a finalidade de combater os excessos perpetrados pelo absolutismo.

Como bem esclarece Fábio Konder Comparato ${ }^{2}$, as instituições do Estado Liberal tendem à neutralização do Poder Público; os seus governantes não tomam iniciativas nem empreendem políticas, apenas administram os negócios do Estado.

${ }^{1}$ Cabe ressaltar que este item tem por finalidade apresentar uma visão histórica geral para que seja possível compreender, ao decorrer do artigo, as transformações que possibilitaram a intervenção judicial em políticas públicas no Brasil. Para uma maior imersão na teoria política e constitucional, veja-se LEAL, Victor Nunes. A divisão de poderes no quadro político da burguesia. In: CAVALCANTI, T. et alli. Cinco estudos. Rio de Janeiro: FGV, 1995. p. 92-113; SIEYÈS, Emannuel. O que é terceiro Estado? Rio de Janeiro: Lumen Juris, 2001; LASSALE, Ferdinand. A essência da constituição. Rio de Janeiro: Lumen Juris, 2001; LENIN, Vladimir Ilitch. O Estado e a revolução. São Paulo: Hucitec, 1987; SCHMITT, Carl. O guardião da constituição. Tradução de: Geraldo de Carvalho. Belo Horizonte: Del Rey, 2007; BINENBOJM, Gustavo. A nova jurisdição constitucional brasileira. Rio de Janeiro: Renovar, 2001.

2 COMPARATO, Fábio Konder. Para viver a democracia. São Paulo: Brasiliense, 1989. p. 105. 
A ideia liberal consistia em entregar a capacidade de criar leis aos representantes do povo, os legisladores, submetendo o governo a um regime de leis que teriam por finalidade controlar a sua atuação e tendo o Judiciário como aplicador imparcial da lei no caso de eventual disputa entre indivíduos ${ }^{3}$

Aos poucos, contudo, por interesse daqueles que se encontravam no poder, o Estado de legalidade deixou de dialogar com as pretensões sociais. É que, como Paulo Bonavides esclarece, no momento em que a burguesia, idealizadora do modelo liberal, se apoderou do controle político da sociedade e passou de classe dominada para classe dominante, não se interessou mais em colocar em prática os princípios criados anteriormente para fomentar o Estado Liberal ${ }^{4}$.

A simples positivação dos direitos não logrou êxito em reparar a abstenção funcional do Estado. Os direitos, por interesses da classe dominante, ainda que garantidos legalmente dificilmente eram transportados do mero papel para a realidade social.

Assim, a liberdade formal garantida pelo liberalismo transformouse na liberdade de oprimir os mais fracos. O Estado Liberal encobriu, por muito tempo, um mundo de desigualdades de fato (econômicas, sociais, políticas e pessoais) ${ }^{5}$, gerando enormes contradições e permanente insatisfação popular. Irremediavelmente, este modelo estatal entrou em crise.

Todas as consequências negativas provocadas pelo Estado de legalidade - individualismo, abstencionismo ou neutralismo estatal, injustiças sociais - ocorreram de forma gradual, e o apogeu se deu na primeira metade do século $\mathrm{XX}$.

Após o período das grandes guerras e da grande depressão, houve a proliferação da positivação dos direitos humanos. Era preciso dar uma resposta imediata, ainda que apenas em plano teórico, às atrocidades perpetradas por tanto tempo pelos agentes públicos.

Surge, então, a partir do século XX, o chamado Estado Social de Direito, um novo modelo político estatal, que coloca o Estado no papel principal de protetor e defensor das garantias sociais e permite uma maior

${ }^{3}$ ROCHA, Luiz Alberti G. S. Novo Perfil do Poder Judiciário Brasileiro. Revista de Direito Constitucional e Internacional. São Paulo, vol. 67, p. 162, Abril / 2009.

4 BONAVIDES, Paulo. Do estado liberal ao estado social. São Paulo: Malheiros, 2009. p. 42

5 Ibid., p. 61 
intervenção estatal na economia, o que não era concebível no modelo do liberalismo extremado. Tal modelo surge com o ideal de afirmar os direitos humanos, mais precisamente os direitos sociais - de segunda geração - e de amenizar as latentes injustiças sociais.

Este novo modelo, como ensina o constitucionalista Paulo Bonavides, "[...] nasceu de uma inspiração de justiça, igualdade e liberdade" e buscou, sobretudo, empregar meios intervencionistas no intento de estabelecer certo equilíbrio na repartição dos bens sociais, ao passo que buscou instituir um regime de garantias concretas e objetivas. ${ }^{6}$

Esta transição institucional do Estado Liberal para o Estado Social não só promoveu uma alteração substancial na concepção da própria instituição estatal, como alterou suas finalidades. José Afonso da Silva, utilizando-se dos dizeres de Elías Dias, explica que o Estado Social é caracterizado pelo propósito de compatibilizar, em um mesmo sistema, o capitalismo, como forma de produção econômica, e a consecução do bem-estar social, o que acabou servindo de base para o neocapitalismo típico do Welfare State ${ }^{7}$.

Com efeito, o que se almeja no Estado Social é justamente a melhoria das condições de vida da sociedade, reduzindo as diferenças e eliminando os motivos de conflitos, através do fomento ao desenvolvimento econômico homogêneo, o que criaria uma situação generalizada de bem-estar. Assim, haveria igualdade porque a todos seria garantido um mínimo de bem estar, o que seria plenamente democrático, capaz de estabelecer a harmonia espontânea a todos os membros do corpo social ${ }^{8}$.

Não obstante a essência do Estado Social consistisse na amortização das lutas de classe e na promoção da tão almejada justiça social através da redução das desigualdades materiais, este modelo institucional não foi capaz, em face da diversidade de interesses sociais e políticos, de consagrar materialmente e democraticamente a maioria dos direitos fundamentais impressos nos diplomas constitucionais.

Primeiro porque a sociedade, em período crítico de transição e de recuperação, ainda estava marcada por resquícios sociais, econômicos e

${ }^{6}$ BONAVIDES, Paulo. Do estado liberal ao estado social. São Paulo: Malheiros, 2009. p. 12.

7 SILVA, José Afonso da. Curso de direito constitucional positivo. São Paulo: Malheiros, 1998. p. 119.

${ }^{8}$ DALLARI, Dalmo de Abreu. O futuro do Estado. São Paulo: Moderna, 1980, p. 141. 
políticos negativos, oriundos das grandes guerras e dos desequilíbrios provocados pelo liberalismo. Segundo porque, muitas vezes, os direitos sociais eram tidos por muitos como meras normas programáticas, ou seja, não autoexecutáveis, que apenas traçavam linhas gerais de ações direcionadas ao Poder Público e que demandavam pesados investimentos a curto, médio e longo prazo.

Por tais razões, a perda gradual da legitimidade e da credibilidade dos estatutos normativos, já abalada, foi inevitável. Por consequência, como um conceito e um ideário novo, capaz de renovar o âmago daqueles que lutam incansavelmente por verdadeiras transformações sociais, emerge formalmente, no Brasil, o Estado Democrático de Direito.

O Brasil adotou expressamente, na Constituição Federal de 1988, em seu art. $1^{\circ}$, o Estado Democrático de Direito como um modelo a ser seguido. Elegeu a soberania, a cidadania, a dignidade da pessoa humana e os valores sociais do trabalho e da livre iniciativa como fundamentos supremos deste "novo" modelo.

O conceito de Estado Democrático não se apresenta, como se poderia supor, como mera justaposição dos conceitos de Estado Democrático e de Estado de Direito. O Estado Democrático se sustenta sob a égide do princípio da soberania popular, que impõe a participação efetiva e direta da sociedade na coisa pública e visa, sobretudo, instrumentalizar o princípio democrático como garantia dos direitos fundamentais da pessoa humana. Já o Estado de Direito se funda, basicamente, na formalidade das leis, elemento puramente formal e abstrato. ${ }^{9}$

Além dos conceitos trazidos pelos componentes destes, incorpora em sua essência um elemento revolucionário: a busca pela transformação do status quo. Assim ensina José Afonso da Silva:

É um tipo de Estado que tende a realizar a síntese do processo contraditório do mundo contemporâneo, superando o Estado capitalista para configurar um Estado promotor de justiça social que o personalismo e o monismo político das democracias populares sob o influxo real não foram capazes de construir. ${ }^{10}$

\footnotetext{
9 SILVA, José Afonso da. Curso de direito constitucional positivo. São Paulo: Malheiros, 1998. p. 119-122.

${ }^{10}$ Ibid., p. 124.
} 
Sob esta nova concepção de constitucionalismo, os direitos fundamentais, como nunca antes, se elevaram ao patamar de garantidores desta justiça social preconizada pelo Estado Democrático de Direito e tornaram-se pré-requisitos para a promoção da liberdade e da dignidade da pessoa humana, garantindo, assim, a igualdade material e social preconizada no texto constitucional.

É necessária, portanto, uma nova postura estatal para se alcançar os objetivos elencados pelo Estado Democrático de Direito idealizados pela Constituição de 1988. A função precípua de transformar a realidade social depende da transformação de todas as formas de expressão do Poder Público - legislativa, executiva e judiciária. Só assim poderá ser garantido o desenvolvimento nacional a fim de atingir, democraticamente, o bem estar social.

\section{DIREITOS FUNDAMENTAIS: POSIÇÃO E SIGNIFICADO NA CONSTITUIÇÃO DE UM ESTADO DEMOCRÁTICO DE DIREITO}

O vínculo existente entre Constituição, direitos fundamentais e Estado de Direito é íntimo e indissociável. O amálgama entre esses elementos, como nos ensina Ingo Wolfgang Sarlet ${ }^{11}$, encontra fundamento legal desde 1789, mais precisamente no art. 16, da Declaração Francesa dos Direitos do Homem e do Cidadão, de 1789, que dispõe que "[...] toda a sociedade na qual a garantia dos direitos não é assegurada nem a separação dos poderes determinada, não possui Constituição".

A partir de então, os direitos fundamentais tornaram-se elementos essenciais, indispensáveis, a qualquer Constituição de um Estado de Direito. O exercício do poder dos Estados constitucionais ficou estritamente vinculado aos limites impostos pelos direitos fundamentais, que se tornaram verdadeiros critérios de legitimação do poder estatal. ${ }^{12}$

Ana Paula Barcellos esclarece que "[...] os direitos fundamentais tem um status diferenciado no âmbito do sistema constitucional e $a$ fortiori do sistema jurídico como um todo". Os direitos fundamentais

11 SARLET, Ingo Wolfgang. A eficácia dos direitos fundamentais. Porto Alegre: Livraria do advogado, 2006. p. 69.

12 Ibid., p. 70-71. 
seriam centralizados e elevados a este patamar, posto que representantes da dignidade humana e dos direitos do homem, autênticos fundamentos tanto do Estado quanto do próprio Direito em si. ${ }^{13}$

A Constituição brasileira de 1988, sem dúvida alguma, ampliou o rol de direitos fundamentais individuais e coletivos. Tal relevância jurídica foi um produto do processo de redemocratização social, política e econômica, realizado pelo Estado brasileiro após vinte longos anos de ditadura militar. ${ }^{14}$

A superação do autoritarismo possibilitou que o Brasil, como Estado Democrático de Direito, reconhecesse, de forma sem precedentes, a importância e o significado dos direitos fundamentais em sua ordem constitucional, restituindo ao povo brasileiro as garantias e liberdades fundamentais antes suprimidas ou aniquiladas pelo governo ditatorial.

Neste contexto histórico, vale dizer que os direitos sociais receberam do texto constitucional especial relevância jurídica, justamente por representarem a própria materialização da dignidade humana, fundamento do Estado Democrático de Direito.

É necessário ressaltar que, apesar da roupagem jurídica constitucional dos direitos sociais ter se apresentado tardiamente com a Constituição de 1988, tais direitos adquiriram força política no Brasil a partir da Revolução de 1930, ocasião em que se buscou atender minimamente os anseios das demandas sociais - principalmente as trabalhistas -, e teve como principal conquista no âmbito jurídico a Consolidação das Leis Trabalhistas, em 1943.

Além dos direitos e garantias previstos no art. $5^{\circ}$ da Magna Carta e dos direitos sociais exemplificados no Capítulo II da mesma, os direitos fundamentais podem ser encontrados em diversos dispositivos ao longo do texto constitucional, como no art. 225, que garante o direito fundamental ao meio ambiente ecologicamente equilibrado.

A positivação constitucional destes direitos revela a sua força sociopolítica, a qual deve ser rigorosamente observada não só pelo Poder Público, mas por todos os integrantes do corpo institucional de um

${ }^{13}$ BARCELLOS, Ana Paula de. O mínimo existencial, os direitos sociais e os desafios de natureza orçamentária. In: SCARLET, Ingo Wolfgang; TIMM, Luciano Benetti (Org.). Direitos fundamentais: orçamento e "reserva do possível". 2 ed. Porto Alegre: Livraria do advogado, 2010. p. 104.

14 SARLET, Ingo Wolfgang. A eficácia dos direitos fundamentais. Porto Alegre: Livraria do advogado, 2006. p. 78. 
Estado Democrático de Direito, como já consolidado em entendimento doutrinário e jurisprudencial.

Para o presente trabalho, concentrar-se-ão os estudos nos direitos sociais por dois motivos: primeiro por exteriorizarem juridicamente as necessidades primárias para o exercício material da dignidade humana; e segundo porque os direitos fundamentais sociais representam o principal objeto das demandas judiciais que versam sobre políticas públicas.

\section{OS DIREITOS SOCIAIS À LUZ DA CONSTITUIÇÃO DE 1988: O PROBLEMA DA EFICÁCIA E APLICABILIDADE}

Os direitos sociais, também chamados de direitos de segunda geração ou direitos de igualdade, são oriundos dos reclames sociais de setores menos favorecidos, os quais ganharam relevância jurídica internacional após o Pacto Internacional dos Direitos Econômicos e Sociais, de 1966, ratificado tardiamente pelo Brasil apenas em 1992.

Pode-se dizer que tais direitos tem por finalidade primordial a realização de uma igualdade substancial, com propósitos compensatórios de séculos de desigualdade fática. Visam, em síntese, o implemento de tarefas de melhoria, distribuição e redistribuição de recursos, bem como o fornecimento de bens jurídicos e sociais essenciais à população, ainda não disponíveis para todos que deles necessitam.

José Afonso da Silva os conceitua da seguinte maneira:

[...] os direitos sociais, como dimensão dos direitos fundamentais do homem, são prestações positivas proporcionadas pelo Estado direta ou indiretamente, enunciadas em normas constitucionais, que possibilitam melhores condições de vida aos mais fracos, direitos que tendem a realizar a igualdade de situações sociais desiguais. São, portanto, direitos que se ligam ao direito de igualdade. $^{15}$

Em última análise, são direitos de exigir prestações frente ao Estado, mas só são plenamente exigíveis se o indivíduo não tiver recursos suficientes ou se não houver oferta suficiente no mercado, isto porque há uma carência relativa de recursos por parte do Estado, que

${ }^{15}$ SILVA, José Afonso da. Curso de direito constitucional positivo. 15 ed. São Paulo: Malheiros, 1988, p. 289-290. 
apesar da elevada carga tributária que impõe aos cidadãos, é incapaz de atender toda e qualquer demanda. ${ }^{16}$

Os direitos sociais foram inseridos no preâmbulo da Constituição Federal de 1988, o que significa que foram incorporados como valores supremos da República. Igualmente, fazem parte do título constitucional destinado aos direitos e garantias fundamentais, e, como consequência, estão subordinados à regra da autoaplicabilidade prevista no $\S 1^{\circ}$ do art. $5^{\circ}$ da Carta constitucional. ${ }^{17}$

Dentre os direitos fundamentais positivados na Constituição de 1988, os direitos sociais, expressos num rol exemplificativo do art. $6^{\circ}$ direito à saúde, à educação, à moradia, ao trabalho -, são os que mais têm suscitado controvérsias a respeito de sua eficácia e aplicabilidade, bem como de sua acionabilidade ou justiciabilidade.

Tais direitos, em sua maioria, demandam obrigações positivas do Estado mediante o oferecimento de prestações materiais, implantação e execução de políticas públicas, que por sua vez, dependem do dinheiro dos cofres públicos.

Em contraposição aos direitos de primeira geração - os direitos civis e políticos, tais como o direito de liberdade, o direito de igualdade, o devido processo legal, o acesso à Justiça, o direito de voto, entre outros -, que não exigem mais que a abstenção do Estado em intervir na esfera dos direitos individuais, os direitos sociais exigem uma postura mais ativa e planejada do Estado, o que dá origem às tantas controvérsias.

Apesar de integrarem os direitos fundamentais, e estarem, portanto, subordinados ao princípio da eficácia plena e aplicabilidade imediata, os direitos sociais esbarram nos limites orçamentários para a sua implementação e dependem direta ou indiretamente de uma infraestrutura bem planejada para a sua fruição.

Ingo Wolfgang Sarlet analisa com maestria este impasse. ${ }^{18}$ Segundo o jurista, há duas posições extremistas: de um lado há quem sustente que as normas definidoras de direitos fundamentais, em boa parte, possuem eficácia apenas nos termos da lei, e dependem, portanto de atuação política e legislativa; do outro lado há quem defenda que

${ }^{16}$ MOREIRA, Reinaldo Daniel. A efetivação judicial dos direitos sociais. Revista de direito constitucional e internacional. São Paulo, n. 75, p. 309, 2011.

${ }^{17}$ MORAES, Alexandre de. Direito constitucional. São Paulo: Atlas, 2009. p. 196.

${ }^{18}$ SARLET, Ingo Wolfgang. A eficácia dos direitos fundamentais. Porto Alegre: Livraria do advogado, 2006. p. 271-281. 
todos os direitos fundamentais possuem aplicabilidade imediata e eficácia plena por força do já mencionado $\S 1^{\circ}$, do art. $5^{\circ}$, da Constituição Federal.

Ainda na visão de Sarlet, não há como pactuar com nenhuma destas posições. Admitir que todos os direitos fundamentais possuem aplicabilidade imediata e eficácia plena seria simplificar a natureza dos direitos fundamentais e equipará-los, equivocadamente, às demais normas constitucionais. Sustentar, contudo, que os direitos fundamentais dependem em sua essência de concretização legislativa e política seria ignorar o significado do principio constitucional da aplicabilidade imediata e da plena eficácia dos direitos fundamentais. ${ }^{19}$

Assim, de acordo com o referido autor, a norma contida no art. $5^{\circ}$, $\S 1^{\circ}$, é norma principiológica, "[...] uma espécie de mandado de otimização (ou maximização), isto é, estabelecendo aos órgãos estatais a tarefa de reconhecer a maior eficácia possível aos direitos fundamentais", e, portanto, o seu alcance depende da análise do caso concreto, ou seja, do direito fundamental em pauta. $\mathrm{O}$ autor adverte, ainda, para o fato de que deve ser observada, contudo, uma presunção a favor da aplicação deste princípio constitucional, ou seja, eventual recusa na aplicação desta norma deverá ser necessariamente fundamentada e justificada. ${ }^{20}$

Defender que o sistema jurídico brasileiro autoriza o juiz a efetivar diretamente as normas constitucionais, sobretudo as normas defensoras dos direitos fundamentais, seria uma posição extremada que não condiz com a realidade jurídica, social e prática.

Em contraposição, defender que os direitos sociais não possuem aplicabilidade imediata e eficácia plena seria, no âmbito jurídico, outorgar à lei mais força que à Constituição, negando sua supremacia no ordenamento jurídico nacional. Já no âmbito sociojurídico, significaria pactuar com as omissões injustificadas praticadas, incompreensivelmente, com certa frequência, pelo Poder Público.

Ainda que se reconheça a eficácia e aplicabilidade dos direitos sociais enquanto normas definidoras de direitos fundamentais, é imperioso ressaltar a dificuldade de concretizá-los, ainda que o Judiciário supra formalmente eventuais lacunas ou omissões normativas.

Os direitos sociais, fatalmente, necessitam de alguns fatores externos ao ordenamento jurídico para a sua concretização.

${ }^{19}$ Ibid.

${ }^{20}$ Ibid., p. 282-283. 
Caracterizam-se, como leciona Ricardo Lobo Torres, (i) pela graduação de sua realização; (ii) pela dependência financeira do orçamento do Estado; (iii) pela liberdade de conformação do legislador quanto às políticas de realização de tais direitos; (iv) por serem insuscetíveis de controle jurisdicional os programas políticos-legislativos, a não ser quando se manifestem em clara contradição com as normas constitucionais ou quando apresentam dimensões pouco razoáveis. ${ }^{21}$

Com efeito, o conteúdo da prestação estatal, objeto dos direitos sociais, dificilmente poderá ser realizado apenas com a imposição da norma constitucional, geralmente geral e abstrata, pois aquele depende, inevitavelmente, de planejamento e atuação direta do Poder Público para a sua realização.

\section{AS POLÍTICAS PÚBLICAS COMO INSTRUMENTO DE CONCRETIZAÇÃO DOS DIREITOS SOCIAIS E O CONTROLE JUDICIAL DE POLÍTICAS PÚBLICAS}

A grande maioria dos direitos sociais, econômicos e culturais depende da existência de uma política, ou da implementação de um serviço para a sua realização. Exigem, inevitavelmente, gastos públicos e, por tal razão, a sua materialização ocorre de forma gradual, impulsionada pelo Poder Público em prol da coletividade. ${ }^{22}$

As políticas públicas são indispensáveis à efetivação de direitos fundamentais e estão condicionadas às ações dos poderes políticos, que, por sua vez, se encontram dependentes dos valores e diretrizes impostos por normas constitucionais impositivas e de observância geral e obrigatória. Em síntese, são instrumentos de efetivação de direitos, a serem utilizados após a análise de custos e benefícios na relação entre

${ }^{21}$ TORRES, Ricardo Lobo. O mínimo existencial, os direitos sociais e os desafios de natureza orçamentária. In: SCARLET, Ingo Wolfgang; TIMM, Luciano Benetti (Org.). Direitos fundamentais: orçamento e "reserva do possível". 2 ed. Porto Alegre: Livraria do advogado, 2010. p. 67.

${ }^{22}$ BARROS, Marcus Aurelio de Freitas. Controle jurisdicional de políticas públicas : parâmetros objetivos e tutela coletiva. Porto Alegre: Sergio Antonio Fabris, 2008. p. 22. 
receitas e despesas, visando distribuir, regular e redistribuir benefícios, a fim de minorar as desigualdades e aumentar o padrão de vida médio. ${ }^{23}$

$\mathrm{Na}$ promoção de políticas públicas, em relação à tripartição de poderes, a cada um é atribuído um importante papel. O poder executivo é o responsável por realizar o planejamento e as diretrizes a serem perseguidas mediante a elaboração de leis orçamentárias e, por fim, executar as políticas públicas que garantem a plena realização destes direitos. Já o Legislativo deve traduzir em leis os direitos sociais constitucionais, justamente por tratar-se de normas programáticas. Ao Judiciário, por fim, cabe o controle das políticas públicas.

Como a atuação dos demais poderes em matéria de políticas públicas tem suscitado diversos questionamentos, seja pela omissão injustificada, seja pela ineficiência das escolhas políticas, não raro, o Judiciário enfrenta demandas requerendo a correção ou até mesmo a implementação de políticas públicas que visam garantir direitos suprimidos ou oprimidos de determinada coletividade.

Principalmente em países cuja desigualdade social salta aos olhos, como é o caso do Brasil, onde ainda é possível encontrar relevantes parcelas da população sem acesso aos direitos sociais básicos como saúde, educação, moradia e trabalho, é comum a busca pela satisfação destes direitos pela via judicial, mormente porque tal situação é oriunda, muitas vezes, da falta de investimento público na garantia destes direitos.

Daí a origem do fenômeno da chamada judicialização das políticas públicas, que traduz a lesão ou ameaça de lesão a direito constitucionalmente garantido, que um determinado grupo social não consegue obter pela via administrativa. Quando o Estado Democrático de Direito, garantidor cardial dos direitos fundamentais, se mantém inerte frente aos ditames constitucionais que impõem a realização dos direitos declarados, inevitavelmente ocorre uma proliferação de demandas buscando a satisfação destes direitos através da intervenção judicial. E, diante de uma demanda, o juiz não pode abster-se de julgar o conflito que lhe é apresentado, vez que, por força da consagração da garantia fundamental da inafastabilidade da jurisdição (art. 5, XXXV, da CF), encontra-se obrigado a apreciar quaisquer questões que lhe são trazidas,

${ }^{23}$ SODRÉ, Habacuque Wellington. As contingencias das demandas individuais frente à questão da universalização dos direitos sociais no contexto da judicialização da política. Revista de Processo. São Paulo, n. 200, p. 279, 2011. 
principalmente quando se trata de dar eficácia e efetividade à garantia constitucional dos direitos sociais.

O Poder Judiciário brasileiro, consciente de seu novo papel e da sua importância na sociedade e na política de um Estado Democrático de Direito, deve proceder a seus julgamentos com olhar e análise além do ordenamento jurídico, tendo em vista os fundamentos e objetivos da República, elencados, respectivamente, nos arts. $1^{\circ}$ e $3^{\circ}$, da Constituição.

Os julgamentos não devem ser apenas pautados na mera aplicação da lei. Devem, sobretudo, se correlacionar com os outros ramos da ciência política e social, para evitar decisões judicialmente legítimas, mas que não possuem efetividade prática, principalmente quando se trata de concretização de direitos coletivos, como é o caso da judicialização das políticas públicas.

As políticas públicas são escolhas políticas e, de regra, são eleitas pelo administrador de forma discricionária no momento de elaboração das leis orçamentárias. Essa discricionariedade, no entanto, não é absoluta; está vinculada, acima de tudo, à Constituição e às leis ordinárias. Assim, o planejamento, bem como a execução, das políticas públicas deve observar os valores do Estado Democrático de Direito, os objetivos da República, bem como os direitos fundamentais expressos na Constituição e nos Tratados Internacionais em que o Brasil for signatário.

É importante frisar que não pode a discricionariedade do poder político se sobrepor aos mandamentos constitucionais. Dito isso, é possível que o Poder Judiciário atue nas questões relativas às políticas públicas, mas somente de modo excepcional, quando provocado, e se a incorreção, ineficiência ou omissão pública importar em clara violação à eficácia e à integridade de direitos sociais e culturais ou em estrita violação legal, fato que deve estar cabalmente comprovado nos autos. ${ }^{24}$

O ponto crucial nesta árdua tarefa atribuída ao Judiciário, no que tange às políticas públicas, é analisar quais direitos constitucionalmente assegurados estão sujeitos ao seu controle. É o que alerta Kazuo Watanabe:

${ }^{24}$ BRASIL. Supremo Tribunal Federal: jurisprudência: pesquisa. Agravo Regimental em Recurso Especial n. 410.715-5/SP, de relatoria do Ministro Celso de Mello, publicado no DJ em 03.02.2006. Disponível em <http://www.stf.jus.br/portal/jurisprudencia/listarJurisprudencia.asp?s1=\%28410715 $\% 2 \mathrm{ENUME} \% 2 \mathrm{E}+\mathrm{OU}+410715 \% 2 \mathrm{EACMS} \% 2 \mathrm{E} \% 29 \&$ base=baseAcordaos $>$. 
A grande dificuldade do Judiciário, diante da existência de inúmeros direitos fundamentais sociais consagrados na Constituição, está em saber se cabe, em relação a todos eles, o seu controle sob a ótica da constitucionalidade. Vale dizer, se todos eles são dotados da possibilidade de tutela jurisdicional, ou alguns deles dependem de prévia ponderação de outros poderes do Estado, consistente em formulação específica de política pública para sua implementação. ${ }^{25}$

A judicialização de políticas públicas, ou seja, a busca da concretização de direitos fundamentais através da intervenção judicial, é legítima tendo em vista o direito de ação, bem como o princípio da inafastabilidade da jurisdição. A discussão, então, gira em torno dos requisitos, na concepção de Kazuo Watanabe, para o "[...] acolhimento, pelo mérito, da pretensão de tutela jurisdicional dos direitos fundamentais sociais, ou seja, a efetiva existência do direito fundamental social tutelável jurisdicionalmente". ${ }^{26}$

Esta, é claro, será uma tarefa árdua a ser enfrentada pelo magistrado quando em confronto com as provas trazidas aos autos e com os fatos delineados pelas partes em juízo. Vale ressaltar que a máxima da aplicabilidade imediata e da eficácia plena dos direitos fundamentais deve ser interpretada sempre em favor daquele que tem a sua dignidade humana suprimida ou oprimida injustificadamente, o que acarreta uma clara violação à lei constitucional.

Esta é a nova diretriz trazida pela Constituição de 1988, pois o Poder Judiciário também é uma das faces do Estado e, portanto, deve atuar em harmonia com os demais poderes na consecução dos objetivos estatais. É, pois, também responsável pela construção de uma sociedade justa e solidária, pelo desenvolvimento social, pela diminuição das desigualdades sociais e pela promoção do bem estar de todos. Como a implementação de políticas públicas é um instrumento para a consecução destes objetivos, o Judiciário tornou-se corresponsável também neste aspecto.

25 WATANABE, Kazuo. Controle jurisdicional das políticas públicas: mínimo existencial e demais direitos fundamentais imediatamente judicializáveis. Revista de Processo. São Paulo, n. 193, p. 13, 2011.

26 Ibid. 


\section{LIMITES À INTERVENÇÃO JUDICIAL EM POLÍTICAS PÚBLICAS}

O Judiciário é legítimo para intervir em matéria de políticas públicas. Ainda que não seja o responsável pela sua implementação ou correção, é o responsável pelo controle de legalidade dos atos do Poder Público e por dar concretude às normas constitucionais, principalmente as que asseguram os direitos fundamentais.

Assim, em matéria de políticas públicas, sempre que houver descumprimento das metas e diretrizes constitucionais pelo Poder Público, bem como atos que contrariem a legalidade e a moralidade administrativa, é cabível o controle judicial.

No entanto, este poder de intervenção não é absoluto. Há limites que devem ser observados pelo magistrado ao se confrontar com este tipo de demanda. A linha entre o poder de atuação do agente público e o poder de atuação judicial é tênue.

É de se imaginar o caos que se instauraria se todos os brasileiros que não usufruem dos seus direitos fundamentais ingressassem em juízo para obter uma tutela jurisdicional efetiva neste sentido e todos os pedidos fossem julgados procedentes. Não só haveria um excesso ainda maior de demandas e uma lentidão ainda maior na prestação jurisdicional, como o impacto no orçamento público seria estrondoso.

E não é só. Haveria também uma afronta ao princípio da isonomia, já que seriam concretizados os direitos fundamentais somente em relação àqueles que ingressassem em juízo ou que tivessem uma representatividade adequada, sem levar em consideração que há inúmeros brasileiros que, à margem da sociedade, desconhecem o significado ou até mesmo a existência dos direitos fundamentais.

Ainda, uma intervenção sem limites do Judiciário na escolha de quais políticas públicas deveriam ser implementadas ou corrigidas poderia quebrar a harmonia entre o Legislativo, o Executivo e o Judiciário, caracterizando verdadeira afronta ao princípio constitucional da tripartição de poderes.

Ao agir em tema de políticas públicas, o Judiciário deve manter o permanente cuidado de não adentrar o espaço reservado ao cenário político, que não pode ter suas atribuições restringidas indiscriminadamente. Frisa-se tratar-se de um controle excepcional, que, segundo Marcus Aurélio de Freitas “[...] não se compadece com exageros de interpretação em relação ao postulado de separação das funções 
estatais, discricionariedade administrativa ou outros argumentos menores que pecam por falta de compreensão do momento atual" .27

As dificuldades da atuação jurisdicional no controle de políticas públicas residem fundamentalmente no respeito à discricionariedade da Administração Pública, na possibilidade de concretização imediata dos direitos fundamentais e nas limitações orçamentárias. A tentativa de solução destes conflitos encontra abrigo nos limites traçados pela doutrina e jurisprudência, quais sejam: a separação de poderes e a democracia; o mínimo existencial; e a reserva do possível.

\subsection{A separação de poderes e a democracia}

A divisão de poderes, na concepção liberal da Revolução Francesa, tinha como objetivo primordial a fiscalização e contenção recíproca de eventuais abusos que pudessem ser cometidos em detrimento do bem-estar social. Assim, ao Executivo caberia gerir o orçamento público na execução das obras e serviços de interesse geral, ao Legislativo caberia a tradução da vontade da maioria em leis, e ao Judiciário a aplicação da lei.

É recorrente o argumento de que a viabilização ou a correção de políticas públicas através da intervenção judiciária representaria uma violação ao princípio da separação de poderes, insculpido no art. $2^{\circ}$ da Carta Política de 1988. Isto porque a definição de políticas públicas seria tarefa do Legislativo; a implementação caberia ao Executivo; sendo que ao Judiciário corresponderia apenas o controle de legalidade dos atos administrativos.

Para Dirley da Cunha Jr., não há que se falar em separação de poderes, uma vez que o poder é uno e indivisível. O que se divide são as funções que compõem o poder estatal, que se manifestam por diversos órgãos do Estado, o que não impede a participação de um Poder na função típica do outro. ${ }^{28}$

Para exemplificar a recorrente participação de um poder na esfera de atuação do outro, Dirley da Cunha Jr. cita alguns exemplos: o poder

${ }^{27}$ BARROS, Marcus Aurélio de Freitas. Controle jurisdicional de políticas públicas : parâmetros objetivos e tutela coletiva. Porto Alegre: Sergio Antonio Fabris, 2008. p. 164.

${ }^{28}$ CUNHA JÚNIOR, Dirley da. Controle judicial das omissões do Poder Público: em busca de uma dogmática constitucional transformadora à luz do direito fundamental à efetivação da constituição. São Paulo: Saraiva, 2004. p. 315. 
que tem o Executivo de vetar projetos de leis aprovados pelo Legislativo; o poder que tem o Legislativo de fiscalizar - através de mecanismos de controle e investigação - os atos dos outros poderes; de emendar projetos de Lei de iniciativa do Executivo; e o poder do Judiciário de controlar a constitucionalidade das leis e a constitucionalidade e legalidade dos demais atos normativos do Poder Público. ${ }^{29}$

Sendo assim, ainda que um Poder exerça atividade que é típica de outro, tal exercício não pode ser considerado um atentado à disposição constitucional de divisão de poderes, pois a independência dos Poderes de que trata a constituição não se caracteriza pela exclusividade no exercício das funções que lhes são atribuídas, mas sim pela predominância no seu desempenho.

Paulo Bonavides chega a afirmar que a teoria da divisão dos poderes foi um instrumento necessário para a afirmação da liberdade, mas atualmente é um princípio decadente em virtude das "[...] contradições e da incompatibilidade em que se acha perante a dilatação dos fins reconhecidos ao Estado e da posição em que se deve colocar o Estado para proteger eficazmente a liberdade do indivíduo e sua personalidade". ${ }^{30}$

$\mathrm{Na}$ visão deste jurista, a técnica rígida de separação de poderes retarda e dificulta a passagem do humano ao social e, portanto, deve ser flexibilizada. Em suas palavras:

A liberdade contra o Estado é uma ideia morta. Ingressamos, como se vê, no seguinte dilema: ou alcançamos a liberdade no Estado - e para tanto se mostrara obsoleto o princípio constitucional clássico -, ou, com a hipertrofia dos fins do Estado, seremos esmagados pesa ascensão do totalitarismo estatal, que já deu, e continua dando, sombrias mostras da maneira impetuosa e da irrefreável desenvoltura com que é capaz de sorrir, a golpes de opressão, a democracia e a liberdade.$^{31}$

\footnotetext{
${ }^{29}$ Ibid., p. 315.

${ }^{30}$ BONAVIDES, Paulo. Do estado liberal ao estado social. São Paulo: Malheiros, 2009. p. 86.

31 BONAVIDES, Paulo. Do estado liberal ao estado social. São Paulo: Malheiros, 2009. p. 86.
} 
Tais razões, ainda na visão de Paulo Bonavides, são poderosas o suficiente para reduzir a visão clássica da tripartição de poderes às suas devidas e modestas proporções na atual configuração contemporânea. ${ }^{32}$

Com efeito, não haveria violação ao princípio da separação de poderes caso a intervenção judicial em matéria de políticas públicas seja para a sua correção seja para a sua implementação - tivesse o condão de adequar a conduta do Poder Público aos preceitos constitucionais, pois estaria o Judiciário dentro do exercício típico das suas funções: o controle dos atos administrativos.

A questão envolvendo recursos públicos (quanto será gasto, como será gasto e com qual finalidade), por outro lado, é decisão própria da esfera Legislativa e Executiva, tanto que a Constituição, ao dispor sobre a competência destes poderes, atribuiu a tais poderes a função de elaboração, execução e controle do orçamento público. ${ }^{33}$

Isto, por si só, poderia ocasionar certa invasão desta matéria pelo Judiciário, em se tratando de controle de políticas públicas, o que poderia produzir um desequilíbrio equivocado, que sufocaria o funcionamento regular e o desenvolvimento da democracia ${ }^{34}$, já que os Poderes Executivo e Legislativo, diferentemente do Judiciário, possuem verdadeiros representantes populares, escolhidos voluntariamente pela sociedade. Daí o argumento de que, além do desrespeito à separação de poderes, haveria violação ao princípio da democracia.

Não obstante tal apontamento, Ana Paula Barcellos reconhece que não há que se falar em democracia se os indivíduos não dispõem de condições básicas de existência digna, vez que "[...] o gozo minimamente adequado dos direitos fundamentais, ou de pelo menos alguns deles, é indispensável para o funcionamento regular da democracia”. Tal constatação, explica, ganha significado ainda mais relevante em países em desenvolvimento, "[...] nos quais uma quantidade significativa da população habilitada formalmente a participar do processo democrático vive em situação de pobreza extrema”. 35

${ }^{32}$ Ibid., p 87.

33 BARCELLOS, Ana Paula. O mínimo existencial, os direitos sociais e os desafios de natureza orçamentária. In: SCARLET, Ingo Wolfgang; TIMM, Luciano Benetti (Org.). Direitos fundamentais: orçamento e "reserva do possível". 2 ed. Porto Alegre: Livraria do advogado, 2010. p. 108.

34 Ibid.

35 BARCELLOS, Ana Paula. O mínimo existencial, os direitos sociais e os desafios de natureza orçamentária. In: SCARLET, Ingo Wolfgang; TIMM, Luciano Benetti 
E, ainda, adverte que "Em condições de pobreza extrema ou miserabilidade, e na ausência de níveis básicos de educação e informação, a autonomia do indivíduo para avaliar, refletir e participar conscientemente do processo democrático estará amplamente prejudicada". Diante desta deficiência social, os indivíduos do corpo social acabam manipulados em suas condições básicas de existência, o que, como consequência, suprime a autonomia crítica da sociedade em face de seus representantes, abrindo espaço para a corrupção, ineficiência e clientelismo, o que prejudica a finalidade das políticas públicas de garantir e promover os direitos fundamentais . ${ }^{36}$

Em um país onde 13,6 milhões de famílias se valem do benefício "Bolsa Família" para complementar a renda familiar abaixo de R \$ 70,00 por pessoa, não há como se falar em atentado à democracia pelo Judiciário quando este intervém na ineficiência ou até mesmo na inexistência de políticas públicas, indispensáveis para o reconhecimento regular da dignidade humana.

Temos ainda muito que percorrer para que a população brasileira, além de acesso aos itens primordiais de sobrevivência, tenha também acesso à formação de consciência crítica e democrática, isenta de qualquer interesse político. Se há alguma intervenção judicial legítima em políticas públicas é justamente aquela que zela pelos direitos fundamentais daqueles que se encontram à margem do sistema democrático brasileiro.

\subsection{A garantia do mínimo existencial}

Não obstante a regra do $\S 1^{\circ}$ do art. $5^{\circ}$, da Constituição Federal, que determina a aplicabilidade imediata e garante a plena eficácia das normas definidoras de direitos fundamentais, não há como defender a posição extremista que afirma que absolutamente todos os direitos fundamentais podem valer-se deste dispositivo constitucional. Ainda mais os direitos sociais, que, como já ressaltado, demandam obrigações positivas do Estado, mediante o oferecimento de prestações materiais e implantação de políticas públicas, que exigem pesados investimentos para a sua realização.

(Org.). Direitos fundamentais: orçamento e "reserva do possível". 2 ed. Porto Alegre: Livraria do advogado, 2010. p. 110.

36 Ibid. 
Não obstante a diretriz constitucional, imaginar que em países em desenvolvimento como o Brasil, que enfrentam gravíssimos problemas sociais, todos os direitos fundamentais seriam prontamente transportados dos textos normativos para a realidade social é concepção por demais ilusória.

Assim, nem todos os direitos fundamentais são imediatamente judicializáveis, ante a limitação de recursos públicos e a necessidade de organização e planejamento administrativo para a sua concretização. No entanto, há uma gama de direitos fundamentais que podem e devem ser imediatamente reclamados. São aqueles que integram o conceito do assim chamado mínimo existencial.

O "mínimo existencial", na visão mais restritiva, é formado pelas condições básicas de sobrevivência, uma fração, ainda que ínfima, da dignidade da pessoa humana. Kazuo Watanabe ensina que, por ser um conceito dinâmico e evolutivo, além de possuir uma variável geográfica e histórica, “[...] o que hoje, pelas condições existentes, pode não ser judicialmente tutelável, poderá vir a sê-lo no futuro, imediato ou mediato, segundo o desenvolvimento do país". Ainda na concepção deste jurista, o mínimo existencial é presidido pelo princípio da proibição de retrocesso e, portanto, tem a sua abrangência ampliada na medida em que melhorem as condições socioeconômicas do país. ${ }^{37}$

A jurisprudência do Supremo Tribunal Federal caminha para o reconhecimento da eficácia jurídica de direitos que compõem o conceito - ainda impreciso e em evolução - do mínimo existencial, principalmente nos casos que versam sobre moradia ${ }^{38}$, educação ${ }^{39}$ e saúde. $^{40}$

$\mathrm{Na}$ mesma direção evolui a jurisprudência do Superior Tribunal de Justiça, consoante se extrai do acórdão do Recurso Especial 1.0868.731/RS, de relatoria do Ministro Antônio Herman Benjamin, que

37 WATANABE, Kazuo. Controle jurisdicional das políticas públicas: mínimo existencial e demais direitos fundamentais imediatamente judicializáveis. Revista de Processo. São Paulo, n. 193, p. 13, 2011.

${ }^{38}$ BRASIL. Supremo Tribunal Federal. Jurisprudência: pesquisa: TF - AgRg 708.667 - j. 28/2/2012.

39 BRASIL. Supremo Tribunal Federal. Jurisprudência: pesquisa: STF - AgRg 639.337 - j. 23/8/2011 - v.u. - rel. José Celso de Mello Filho, STF; AgRg 785.154 j. 28/2/2012, STF; AgRg 594.018-7 - 2. ${ }^{a}$ Turma - j. 23/6/2009, STF; AgRg 603.575 2. ${ }^{a}$ Turma - j. 20/4/2010.

${ }^{40}$ BRASIL. Supremo Tribunal Federal. Jurisprudência: pesquisa: AgRg n.47, Sessão Plenária, julgado em. 17/3/2010; AgRg n. 650.359, j. 7/2/2012. 
reconhece ser o direito à saúde um direito fundamental que integra a noção do mínimo existencial. Em seu entender, o conceito de mínimo existencial não se resume ao mínimo que se exige para sobrevivência do ser humano. O conteúdo daquilo que seja o mínimo existencial abrangeria, também, as condições socioculturais, que, para além da questão da mera sobrevivência, asseguram ao indivíduo um mínimo de inserção na vida social. ${ }^{41}$

No caminho para a construção de um país mais justo e igualitário, estamos em busca da construção de um mínimo existencial que se afaste do mínimo à existência e se aproxime do mínimo necessário à dignidade humana.

\subsection{A reserva do possível}

A implementação de uma política pública depende primordialmente dos recursos financeiros disponibilizados pelo orçamento público. Em relação à inexistência ou à ineficiência de políticas públicas, a justificativa usualmente utilizada pela Administração Pública é justamente a carência de recursos.

Em vista disso, passou-se a sustentar que os direitos sociais a prestações materiais estariam subordinados a uma reserva do possível, que seria caracterizada por três aspectos: (i) a real disponibilidade fática dos recursos para a efetivação dos recursos sociais; (ii) a disponibilidade jurídica dos recursos materiais e humanos; (iii) o problema da proporcionalidade da prestação, em especial quanto a exigibilidade e razoabilidade do direito. ${ }^{42}$

Dirley da Cunha Jr. explica que a ideia da reserva do possível é originária da doutrina e jurisprudência germânica que entende que o reconhecimento dos direitos subjetivos a prestações depende da disponibilidade de recursos públicos, bem como que tal decisão insere-se

41 BRASIL. Superior Tribunal de Justiça. Consultas: Jurisprudência: pesquisa: Recurso Especial n. 1.068.731, j. 17/2/2011.

42 SARLET, Ingo Wolfgang. Eficácia e efetividade de direitos fundamentais, controle judicial de políticas públicas e separação de poderes: anotações ao AgRg no Adin 708.667 do STF. Revista dos Tribunais, n. 921, p. 471, 2012. 
no espaço discricionário das opções do governo e do parlamento, através da composição dos orçamentos públicos. ${ }^{43}$

$\mathrm{O}$ autor ainda adverte que "a doutrina nacional, lamentavelmente [...], vem acolhendo comodamente essa criação do direito estrangeiro, aceitando-se indiscriminadamente como obstáculo ao reconhecimento dos direitos originários a prestações", não obstante ter sido a reserva do possível desenvolvida em um contexto jurídico e social distinto da realidade brasileira. ${ }^{44}$

Para Ada Pellegrini Grinover, a alegação pelo Poder Público da falta de recursos não é suficiente e deverá ser provada pela própria Administração, sendo aplicável, neste particular, a inversão do ônus da prova previsto no art. $6^{\circ}$, VIII, do Código de Defesa do Consumidor, ou a flexibilização do ônus da prova previsto no art. 333, do Código de Processo Civil, justamente para atribuir a carga da prova à parte que estiver mais próxima dos fatos e tiver mais facilidade de prová-los. ${ }^{45}$

O mesmo entendimento é compartilhado por Ingo Wolfgang Sarlet. Segundo ele, a impossibilidade de atendimento da demanda diante da alegação da reserva do possível deve ser demonstrada pelo Poder Público, a quem incumbe o ônus da prova, a fim de que não se torne um entrave burocrático na concretização dos direitos sociais prestacionais.

Ainda que a insuficiência de recursos seja devidamente comprovada, deverá ser determinado ao Poder Público que inclua na próxima proposta orçamentária a verba necessária para a implementação da política pública. ${ }^{46} \mathrm{E}$ como a lei orçamentária permite a transposição de verbas, pois não é vinculante, em caso de descumprimento do orçamento, ao Judiciário caberá aplicar a sanção prevista no $§ 5^{\circ}$, do artigo 461, do Código de Processo Civil.

Em síntese, a proposta consiste em uma obrigação de fazer em duas etapas: a primeira seria a inclusão no orçamento da verba necessária à implantação da política pública, a segunda seria a obrigação de aplicar a verba prevista no orçamento para o adimplemento da obrigação fixada.

${ }^{43}$ CUNHA JÚNIOR, Dirley da. Controle judicial das omissões do Poder Público: em busca de uma dogmática constitucional transformadora à luz do direito fundamental à efetivação da constituição. São Paulo: Saraiva, 2004, p. 307.

${ }^{44}$ Ibid., p. 308.

${ }^{45}$ GRINOVER, Ada Pellegrini. O controle de políticas públicas pelo Poder Judiciário. Doutrinas essenciais de direito constitucional. São Paulo, n. 4, p. 563, 2011. ${ }^{46}$ Ibid. 
Para Sarlet, todos os aspectos concernentes à reserva do possível devem ser analisados e exigem uma solução sistemática e constitucionalmente adequada, para que não sirvam como barreira intransponível, mas como instrumento que se soma às demais garantias de proteção aos direitos fundamentais (e sociais), tendo em vista o princípio da máxima eficácia e efetividade de todos os direitos fundamentais.

Assim, pode-se concluir que o argumento da indisponibilidade de recursos não pode ser usado como escusa do administrador público na efetivação dos direitos fundamentais, tampouco como óbice à intervenção judicial, mas deve ser levado em consideração que os direitos fundamentais a prestações não são absolutos, na medida em que devem observar a reserva do possível, bem como os critérios da proporcionalidade e razoabilidade.

\section{A CRÍTICA OPERACIONAL AO CONTROLE JUDICIAL DE POLÍTICAS PÚBLICAS}

As demandas envolvendo a discussão sobre políticas públicas geralmente são muito complexas, envolvem fatores socioeconômicos que muitas vezes fogem da esfera de atuação judiciária, que não detém instrumentos técnicos suficientes para avaliar o impacto de suas decisões nestas demandas. Além disso, os limites impostos à atuação judicial - a separação de poderes, a reserva do possível e a garantia do mínimo existencial - são julgamentos imprecisos, sujeitos a uma extensa gama de interpretações.

Cappelletti já advertia sobre esta questão ao afirmar que os juízes ordinários não são os mais adaptados a resolver complexos problemas sociais, econômicos ou políticos e que às Cortes ordinárias faltam os recursos de que dispõem os demais Poderes para realizarem as pesquisas necessárias para uma ponderada decisão desses complexos problemas. Ainda chamou a atenção para o fato de que os juízes ordinários, por temperamento, educação e idade, são geralmente muito conservadores para poderem absorver adequadamente uma tarefa dinâmica num mundo em rápida transformação. ${ }^{47}$

${ }^{47}$ CAPPELletTi, Mauro. Processo, ideologias e sociedade. Tradução de: Elício de Cresci Sobrinho. Porto Alegre: Sérgio Antônio Fabris, 2008. p. 18. 
Ana Paula Barcellos afirma que "nem o jurista, e muito menos o juiz, dispõem de elementos ou condições de avaliar, sobretudo em demandas individuais, a realidade da ação estatal como um todo". O que se quer dizer é que muitos fatos no âmbito jurídico são ignorados, o que pode levar à realização de uma imediata "microjustiça", mas que desconsidera a "macrojustiça"; ou seja, a "justiça" é realizada apenas no caso concreto, direcionada àqueles que detêm o poder de informação, organização para acessar o Judiciário, o que pode desencadear amplas distorções no sistema de políticas públicas em âmbito global. ${ }^{48}$

Tal preocupação merece atenção, pois muitas vezes "o juiz não detém de informações completas sobre as múltiplas necessidades que os recursos públicos devem acudir ou mesmo sobre os reflexos não antecipados que uma determinada decisão pode desencadear" ${ }^{49}$.

Com isso pode-se concluir que o Judiciário deve estar preparado para atuar no controle de políticas públicas, que envolvem, entre outras coisas, o estudo e a físcalização dos gastos públicos e recursos orçamentários, bem como pelo acompanhamento de metas definidas em leis orçamentárias, convênios e diversos outros documentos produzidos pelas instâncias governamentais, tendo em vista a realização da macrojustiça, e não apenas da microjustiça. ${ }^{50}$

Surge, portanto, uma necessidade inadiável de se repensar a atuação jurisdicional para uma tutela efetiva em demandas que versam sobre políticas públicas, justamente por serem de extrema complexidade e por possuírem efeitos nitidamente coletivos. Por tal razão deve-se ter cuidado ao se proferir uma decisão, pois esta possui vasto - até mesmo imensurável! - alcance.

Verifica-se que o Poder Judiciário brasileiro, no mais das vezes, sequer analisa os efeitos das decisões proferidas de cunho individual. As questões tornam-se ainda mais complexas quando possuem caráter social e coletivo - no sentido de que uma decisão individual é capaz de gerar

${ }^{48}$ BARCELLOS, Ana Paula. O mínimo existencial, os direitos sociais e os desafios de natureza orçamentária. In: SCARLET, Ingo Wolfgang; TIMM, Luciano Benetti (Org.). Direitos fundamentais: orçamento e "reserva do possível". 2 ed. Porto 49 Ibid. Alegre: Livraria do advogado, 2010. p. 115.

${ }^{50}$ BARROS, Marcus Aurelio de Freitas. Controle jurisdicional de políticas públicas: parâmetros objetivos e tutela coletiva. Porto Alegre: Sergio Antonio Fabris, 2008. p. 61. 
consequências para toda a coletividade, como a concessão individual de remédios de alto custo.

Se a demanda é coletiva, ou ainda, individual de caráter coletivo, há de se pensar nos efeitos produzidos pela prolação de uma sentença. Não só pensar, como estudar a viabilidade, seus efeitos e consequências. Por vezes, a falta de análise crítica dos efeitos de uma decisão poderá gerar um desequilíbrio de recursos indesejado, afetando reflexamente outros setores tão ou mais importantes que o que foi decidido judicialmente.

Virgilio Afonso da Silva chega a afirmar que as políticas públicas devem ser pensadas coletivamente, algo que os juízes não fazem. Aduz o autor que "os juízes, ao tratarem os problemas dos direitos sociais como se fossem problemas iguais ou semelhantes àqueles relacionados a direitos individuais, ignoram o caráter coletivo dos primeiros". 51

E conclui:

Isso significa que, embora o ativismo judicial seja uma possibilidade, ele depende de diversas mudanças estruturais na educação jurídica, na organização dos tribunais e, sobretudo nos procedimentos judiciais, para que passe a ser possível tratar os direitos sociais e sobre eles decidir de forma coletiva.

$[\ldots]$

Se isto está correto, e se o Judiciário não é capaz de pensar em saúde, educação, moradia etc, de forma coletiva e global, talvez devesse deixar essa tarefa para o processo político. $^{52}$

Com isso não se quer dizer que o Judiciário não deva apreciar as questões que lhe são submetidas; isso, inclusive, não seria viável, pelo princípio constitucional da inafastabilidade da jurisdição. Mas, repise-se, é necessário (re)avaliar se determinada decisão, concedida no intuito de beneficiar a coletividade, ao contrário, não acabará por prejudica-la.

Os custos para a execução de uma sentença de caráter coletivo devem ser cuidadosamente avaliados, pois os impactos são reflexos a toda sociedade. Na prática, "[...] falta preparo aos juízes para analisarem a escassez econômica, bem como falta preparo para as pastas públicas

51 SILVA, Virgilio Afonso da. Direitos sociais: fundamentação, judicialização e direitos sociais em espécie. Rio de Janeiro: Lumen Juris, 2008, p. 595-596.

52 Ibid., p. 595-596. 
levarem tais dados aos processos" ${ }^{, 53}$, o que pode resultar, muitas vezes, em decisões equivocadas ou arbitrárias.

Por tais razões, nestas demandas que envolvem uma decisão tão complexa melhor, seria estabelecer um planejamento conjunto entre o juiz ou Tribunal prolator da decisão e os membros de outros Poderes para a realização de políticas públicas eficientes.

Com a atuação conjunta dos três poderes não mais se falaria em violação constitucional à tripartição de poderes, tampouco em usurpação de competência pelo Judiciário: as políticas públicas seriam encaradas como atos típicos da soberania, que é una, exercida em seu sentido pleno através da legislação, administração e jurisdição. Para tanto seria necessário repensar não só a atuação jurisdicional como também a dimensão dos diálogos institucionais.

\section{JUDICIALIZAÇÃO DE POLÍTICAS PÚBLICAS: NECESSIDADE DE UM NOVO PROCEDIMENTO?}

As demandas coletivas sobre políticas públicas, que visam reformá-las ou implementá-las, possuem peculiaridades que fogem da "normalidade" processual da prática jurídica. Nem os juízes nem as partes estão habituados a atuarem em causas dessa espécie.

Tais ações, para que se chegue a solução que atenda realmente os objetivos constitucionais, bem como o interesse público, exigem sensibilidade, razoabilidade e criatividade judiciária, para que o procedimento seja flexibilizado e, assim, atenda verdadeiramente aos interesses sociais, o que, na prática, não se pode exigir de todos os magistrados - até mesmo porque, para tanto, não há previsão legal.

Não por acaso, foi elaborado, pelos eminentes professores Ada Pellegrini Grinover e Kazuo Watanabe, com a colaboração dos pesquisadores do Cebepej (Centro Brasileiro de Estudos e Pesquisas Judiciais) e de professores e alunos do Curso de Mestrado em políticas públicas da Fundação Getúlio Vargas, um Anteprojeto de Lei ${ }^{54}$

${ }^{53}$ SODRÉ, Habacuque Wellington. A contingência das demandas individuais frente à questão da universalização dos direitos sociais no contexto da judicialização da política. Revista de Processo. São Paulo, n. 200, p. 279, 2011.

54 GRINOVER, Ada Pellegrini et. alii. Anteprojeto de Lei. Disponível em <http://direitoprocessual.org.br/content/view/143>. Acesso em 13/09/2012. 
preliminar que prevê um procedimento especial para o controle e intervenção em políticas públicas pelo Poder Judiciário.

Nesta proposta, o procedimento para o controle e a intervenção judicial em políticas públicas é dividido em duas fases, administrativa e judicial, sendo que ambas tramitariam judicialmente.

A fase administrativa, em síntese, seria uma "oportunidade" para a Administração Pública justificar, perante o Judiciário e a parte contrária, em 30 dias, prorrogáveis por mais 30, o porquê da omissão (total ou parcial), e apresentar um cronograma para o eventual atendimento do pedido da petição inicial, sob pena de multa prevista no parágrafo único do art. 14, do Código de Processo Civil.

Frustrada a fase administrativa, ou seja, não havendo acordo entre as partes, inicia-se o procedimento judicial, após o juízo de admissibilidade realizado pelo mesmo julgador. A competência tanto para a fase administrativa, quanto para a fase judicial, é da justiça ordinária, estadual ou federal, salvo em hipóteses de cabimento de ações constitucionais.

$\mathrm{O}$ procedimento judicial, previsto neste anteprojeto, apresenta prazos próprios, bem como possibilita a alteração da coisa julgada em fase de execução de sentença (art. 14, parágrafo único), autoriza a participação do amicus curiae (também permitida na fase administrativa), além de prever meios alternativos de solução de conflitos.

Ainda, possibilita a notificação dos legitimados ativos acerca do ajuizamento de demandas individuais que versem sobre direitos subjetivos que possam interferir em políticas públicas a fim de que o Ministério Público e os demais legitimados ajuízem ações coletivas para corrigir ou implementar a política pública em questão.

$\mathrm{O}$ art. 19 do Anteprojeto prevê a reunião dos processos em primeiro grau, quando vários deles tiverem por objeto políticas públicas relativas ao mesmo ente político, para julgamento conjunto, independentemente de conexão.

Uma das propostas mais interessantes é a que prevê a viabilização de um Cadastro Nacional de Processos sobre Políticas Públicas, a ser realizado pelo Conselho Nacional de Justiça, para que os órgãos interessados e a sociedade em geral possam ter acesso às informações relevantes relacionadas com tais demandas. Esta proposta, além de dar corpo ao princípio da publicidade, teria o condão de coibir o Poder Público de cometer abusos em matéria de políticas públicas. Seria mais 
uma medida muito bem-vinda, direcionada ao agir político, a fim de evidenciar as falhas perpetradas pelos agentes públicos.

Enfim, o Anteprojeto prevê uma série de medidas judiciais que se divergem do procedimento das demais ações coletivas, bem como do procedimento previsto no Código de Processo Civil, o que contribui para a elucidação do tema e torna ainda mais claro a necessidade de modernizar a estrutura do Poder Judiciário, para que este possa atender as demandas coletivas sobre políticas públicas, que tem se tornado uma realidade cada vez mais recorrente nos tribunais.

Não é a intenção analisar pormenorizadamente todos os aspectos do referido Anteprojeto, até porque o mesmo segue sendo modificado, tendo os professores Ada Pellegrini Grinover e Kazuo Watanabe se empenhado em percorrer o Brasil a fim de discutir e aprimorar seu conteúdo junto à comunidade jurídica e acadêmica. $O$ que se quer demonstrar é que o procedimento envolvendo judicialização de políticas públicas para a efetivação dos direitos fundamentais difere em diversos aspectos do procedimento das ações coletivas, e ainda mais dos procedimentos direcionados às demandas individuais previstos no Código de Processo Civil.

Independentemente do rumo deste Anteprojeto, deve-se atentar para o fato de que tais ações envolvem questões que não encontram previsão legal, e que necessitarão de flexibilização do procedimento e criatividade judiciária para que seja realmente garantida uma tutela jurisdicional efetiva e uma verdadeira implementação do Estado Democrático de Direito.

\section{CONSIDERAÇÕES FINAIS}

O Estado Democrático de Direito vinculou o poder estatal aos princípios e garantias fundamentais, que passaram a representar o critério de legitimação e impor limites ao agir dos Poderes Legislativo, Executivo e Judiciário.

Somente o Estado em todas as suas formas de expressão poderá realizar o verdadeiro desenvolvimento social, o que somente será alcançado por meio do planejamento e de uma política de desenvolvimento que conte com a atuação conjunta dos três poderes. Para tanto, é necessário alterar as suas bases de sustentação e modificar a orientação do movimento sociopolítico excludente. 
Os esforços de apenas um dos poderes, sem a colaboração do outro, pode reduzir desigualdades e injustiças somente em casos isolados, realizando a chamada microjustiça. $\mathrm{O}$ verdadeiro desenvolvimento nacional, idealizado pelo art. $3^{\circ}$ da Constituição da República, só será atingido se houver esforços concomitantes entre o Legislativo, o Judiciário e o Executivo.

Com a proliferação de demandas envolvendo a discussão em torno das políticas públicas, teve o Judiciário que se despir dos resquícios do liberalismo clássico, que impedia uma atuação mais enérgica na sociedade civil, ao mesmo tempo em que se incumbiu do dever de garantir os preceitos constitucionais, principalmente os que asseguram a concretização e efetivação dos direitos fundamentais.

Assim, a doutrina e a jurisprudência acabaram por traçar os limites a uma possível intervenção judicial em políticas públicas. É possível a intervenção sempre que houver descumprimento legal infraconstitucional ou constitucional, exercendo o Judiciário, aí, o controle de constitucionalidade e legalidade dos atos do Poder Público. É também possível a determinação de implementação de políticas públicas ao Poder Público pelo Judiciário, desde que seja para garantir o mínimo existencial à população e desde que dentro dos limites do orçamento público.

O controle jurisdicional de políticas públicas talvez permita criar um compromisso maior do gestor público com relação à destinação de verbas públicas. É mais um instrumento de vigilância direcionado ao Poder Público, já contaminado pela falta de credibilidade social. Além disso, propicia um caminhar saudável em direção à concretização dos direitos fundamentais a nível coletivo, bem como vai de encontro aos objetivos da República.

Para uma solução que atenda realmente aos objetivos constitucionais, bem como ao interesse público, os juízes devem se servir de extrema sensibilidade, razoabilidade e criatividade judiciária, ante a relevância do bem tutelado por estas demandas. Na prática, porém, este comportamento não pode ser exigido indiscriminadamente dos magistrados.

Por tal razão, hoje já se discute a necessidade de um procedimento especial que delimita a atuação judicial em políticas públicas. Exemplo desta preocupação jurídica é a elaboração de um Anteprojeto, encabeçado por Ada Pellegrini Grinover e Kazuo Watanabe, 
que segue sendo discutindo, regrando o procedimento para o controle e a intervenção judicial em políticas públicas.

O Anteprojeto, ao prever uma série de medidas judiciais que divergem do procedimento das demais ações coletivas, é provocativo, e contribui para a elucidação do tema, tornando ainda mais clara a necessidade de modernizar a estrutura do Poder Judiciário em relação a esta matéria, para que realmente seja garantida uma tutela jurisdicional efetiva e capaz de satisfazer as necessidades da população brasileira.

Disso tudo se extrai que o fenômeno da judicialização das políticas públicas é uma alternativa para garantir uma maior efetividade aos direitos fundamentais a nível coletivo, reduzindo a dicotomia entre o discurso político - muitas vezes inutilizado no decorrer do mandado - e a realização de políticas públicas que assegurem a dignidade humana em um país ainda carente de sensibilidade e igualdade social.

A possibilidade de garantia de direitos fundamentais através da judicialização não é e não será a solução ideal e única para o extermínio das desigualdades no país, tampouco garantirá o pleno desenvolvimento social e econômico tão almejado, nem assegurará, por si só, a igualdade material que se espera em um Estado Democrático de Direito. Mas é, por certo e sem sombra de dúvidas, um atuar em direção à consolidação da dignidade humana a nível coletivo.

Trata-se, portanto, de uma via alternativa para dar guarida àqueles que possuem os seus direitos básicos de existência suprimidos e oprimidos pela sociedade e pelo Poder Público, o que não se pode admitir no atual estágio evolutivo do ordenamento jurídico nacional.

\section{REFERÊNCIAS}

BARCELLOS, Ana Paula. O mínimo existencial, os direitos sociais e os desafios de natureza orçamentária. In: SCARLET, Ingo Wolfgang; TIMM, Luciano Benetti (Org.). Direitos fundamentais: orçamento e "reserva do possível". 2. ed. Porto Alegre: Livraria do advogado, 2010.

BARROS, Marcus Aurélio de Freitas. Controle jurisdicional de políticas públicas: parâmetros objetivos e tutela coletiva. Porto Alegre: Sergio Antonio Fabris, 2008.

BONAVIDES, Paulo. Do estado liberal ao estado social. São Paulo: Malheiros, 2009. 
Ciência Política. 19. ed. São Paulo: Malheiros, 2012.

CAPPELLETTI, Mauro. Processo, ideologias e sociedade. Tradução de: Elício de Cresci Sobrinho. Porto Alegre: Sérgio Antônio Fabris, 2008.

COMPARATO, Fábio Konder. Para viver a democracia. São Paulo: Brasiliense, 1989.

CUNHA JÚNIOR, Dirley da. Controle judicial das omissões do Poder Público : em busca de uma dogmática constitucional transformadora à luz do direito fundamental à efetivação da constituição. São Paulo: Saraiva, 2004.

DALLARI, Dalmo de Abreu. O futuro do Estado. São Paulo: Moderna, 1980.

GRINOVER, Ada Pellegrini. O controle de políticas públicas pelo Poder Judiciário. Doutrinas essenciais de direito constitucional. São Paulo, n. 4, 2011.

MONTESQUIEU, Charles Louis de Secondat, baron de la Brède et de. O espírito das leis. Tradução de: Fernando Henrique Cardoso e Leôncio Martins Rodrigues. Brasília: UnB, 1995.

MORAES, Alexandre de. Direito constitucional. São Paulo: Atlas, 2009.

MOREIRA, Reinaldo Daniel. A efetivação judicial dos direitos sociais. Revista de direito constitucional e internacional. São Paulo, n. 75, 2011.

SARLET, Ingo Wolfgang. A eficácia dos direitos fundamentais. Porto Alegre: Livraria do advogado, 2006.

. Eficácia e efetividade de direitos fundamentais, controle judicial de políticas públicas e separação de poderes: anotações ao AgRg. 708.667 do STF. Revista dos Tribunais, n. 92, 2012. 
SILVA, José Afonso da. Curso de direito constitucional positivo. 15. ed. São Paulo: Malheiros, 1998.

SILVA, Virgilio Afonso da. Direitos sociais fundamentação, judicialização e direitos sociais em espécie. Rio de Janeiro: Lumen Juris, 2008.

SODRÉ, Habacuque Wellington. As contingencias das demandas individuais frente à questão da universalização dos direitos sociais no contexto da judicialização da política. Revista de Processo. São Paulo, n. 200, 2011.

TORRES, Ricardo Lobo. O mínimo existencial, os direitos sociais e os desafios de natureza orçamentária. In: SCARLET, Ingo Wolfgang; TIMM, Luciano Benetti (Org.). Direitos fundamentais: orçamento e "reserva do possível". 2 ed. Porto Alegre: Livraria do advogado, 2010.

WATANABE, Kazuo. Controle jurisdicional das políticas públicas: mínimo existencial e demais direitos fundamentais imediatamente judicializáveis. Revista de Processo. São Paulo, n. 193, 2011.

WEFFORD, Francisco C. (Org.). Os clássicos da política. 13. ed. São Paulo: Ática, 2006. v. 1. 